\title{
Compact Multiband Printed IFA on Electromagnetic Band-Gap Structures Ground Plane for Wireless Applications
}

\author{
Dalia Elsheakh and Esmat Abdallah \\ Microstrip Department, Electronics Research Institute, ELtahrir Street, Dokki, Giza 12622, Egypt \\ Correspondence should be addressed to Dalia Elsheakh; daliaelsheakh@gmail.com
}

Received 1 October 2012; Accepted 28 November 2012

Academic Editor: Ramon Gonzalo

Copyright (C) 2013 D. Elsheakh and E. Abdallah. This is an open access article distributed under the Creative Commons Attribution License, which permits unrestricted use, distribution, and reproduction in any medium, provided the original work is properly cited.

The fourth mobile generation requires of multistandard operating handsets of small physical size as well as has an increasing demand for higher data rates. Compact multiband printed inverted-F antennas (IFAs) for available wireless communications are proposed in this paper. A new design of a printed IFA based on a uniplanar compact EBG concept is proposed. An L-loaded printed IFA shaped over an artificial ground plane is designed as the main antenna to cover the GSM, LTE, UMTS, bluetooth, and WLAN. The multi-band is created by means of an electromagnetic band-gap (EBG) structure that is used as a ground plane. Different shapes of uniplanar EBG as ring, split ring resonator, and a spiral rather than mushroom-like structure are investigated. The proposed antenna is built on the uniplanar EBG ground plane with a size of $35 \times 45 \mathrm{~mm}^{2}$, which is suitable for most of the mobile devices.

\section{Introduction}

The current upsurge in wireless communication systems has forced antenna engineering to face new challenges, which include the need for wide bandwidth, small-size, highperformance, robustness, ease of mounting on a host surface and low-cost antennas. To have compatible uses for a wide range of applications by fulfilling mobility requirement and holding up the performance as well as the capability of obtaining dual and triple frequency operations are challenges [1].

Printed IFAs offer an attractive solution to a compact and ease-low-cost design of modern wireless communication systems due to having the above advantages. Printed inverted-F antenna is a simple and compact radiator; however, it cannot radiate efficiently near a perfect electric conductor (PEC) ground plane due to the reverse image currents. Also, printed IFAs suffer from a number of disadvantages as compared to conventional nonprinted antennas. Some of their major drawbacks are the narrow bandwidth, $\lambda / 4$ length, low gain, and surface wave excitation that reduce radiation efficiency.
To solve the problem of their narrow bandwidth, several techniques can be used [2-4]. A thicker substrate with a low dielectric constant or a ferrite composition provides a wider bandwidth but this approach leads to no low-profile designs and an increase in size. Noncontacting feeding methods such as proximity/aperture coupled can be used to improve the impedance bandwidth, but this is difficult to fabricate. Another possibility is multiresonator stack configuration with the inconvenience of resulting a large thickness prototype $[5,6]$.

To overcome the problem of large size, the basic antenna miniaturization techniques can be classified into lumpedelement loading, material loading, the use of ground planes, short circuits, and the antenna environment, as applied antenna on electromagnetic band-gap structures. Based on this, many attempts to design compact antennas have been studied in the past [7]. Among various EBG structures, uniplanar EBG designs such as the mushroom-like structure [8] received a great potential for wireless communication systems because of their low-profile configurations. One important application of EBG structures is to serve as the 


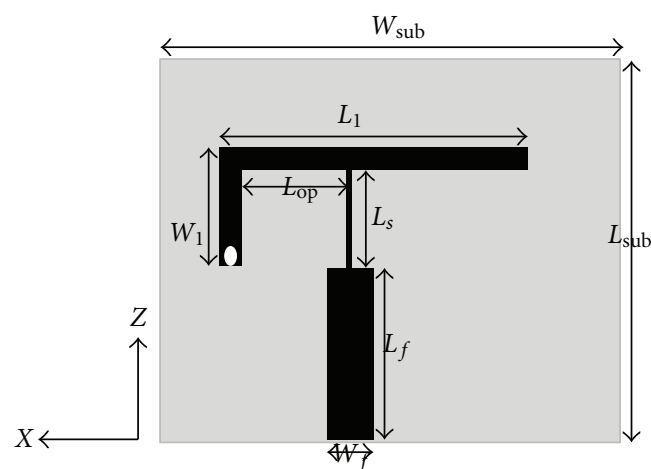

(a)

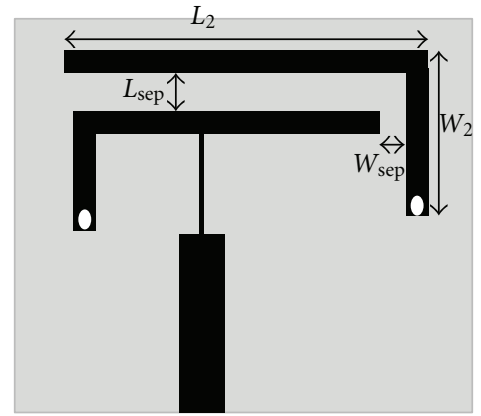

(b)

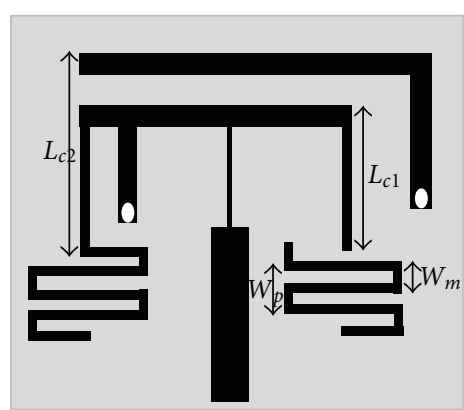

(c)

FIGURE 1: The configuration of (a) conventional IFA, (b) L-loaded IFA and (c) meandered L-loaded IFA.

ground plane for low-profile antennas [9-12]. The EBG structures are usually periodic arrangements of metallic or dielectric elements that exhibit band-gap characteristics which are sensitive to the permittivity, thickness of the substrate, and most importantly to the EBG geometry. The important properties of EBG are the ability to guide and control the propagation of electromagnetic waves, the suppression of surface waves within the band-gap range, and hence the improvement of the antenna performance by reducing crosspolarization, back radiation, and mutual coupling [13, 14]. Most of researches were focused on the three-dimensional EBG structures which are complicated, heavy, and difficult to integrate with microwave circuits. To avoid complexity, planar 2D EBG-like mushroom shape, split-ring-resonatorlike shape, spiral shape, and so forth were suggested [15-17].

In this paper, the performance of L-loaded printed IFAs with meandering shape at the open end near the edge of a PEC ground plane is first investigated. Then different shapes of mushroom-like high impedance surface (HIS) EBG structures are used to improve the antenna parameters such as broaden bandwidth and efficiency and reduce the electrical size. Satisfactory results are obtained. All simulations are carried out using the EM commercial simulator, HFSS version 13.0.

\section{Design of Printed IFAs}

This section gives the details of the design procedure of the proposed multiband printed IFA antenna. It starts by the design of a conventional printed IFA that operates at $5.2 \mathrm{GHz}$, over a conventional ground plane as shown in Figure 1(a). The printed IFA dimensions are length $L_{1}=21.75 \mathrm{~mm}$ with shorting wall size $W_{1}=7.4 \mathrm{~mm}$ and ground plane size $L_{\text {sub }} \times$ $W_{\text {sub }}=35 \times 45 \mathrm{~mm}^{2}$. The distance between the feed and the short end $L_{\text {op }}=16.5 \mathrm{~mm}$ with $L_{\text {sep }}$ and $W_{\text {sep }}$ are $6.5 \times 4.5 \mathrm{~mm}^{2}$ and all transmission line widths are $2 \mathrm{~mm}$. Then, two different approaches were investigated to introduce more bands to the printed IFA. The first approach is using L-loaded printed IFA as shown in Figure 1(b) with length and width $L_{2} \times$ $W_{2}=30 \times 12 \mathrm{~mm}^{2}$. The antenna resonates at dual resonant

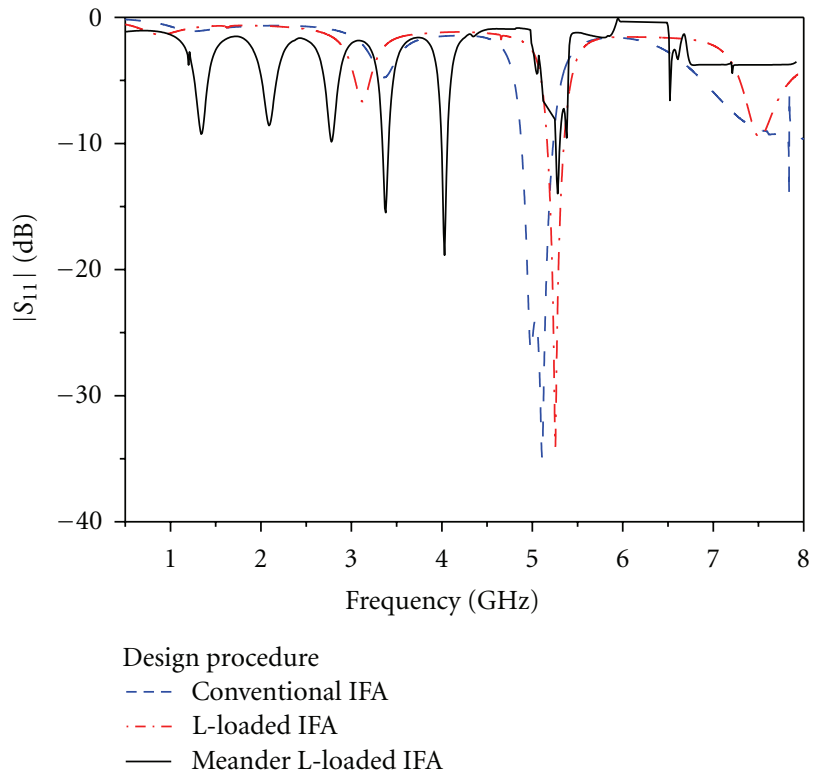

FIGURE 2: Simulated $\left|S_{11}\right|$ of the design antenna procedures with conventional ground.

frequencies $3.1 \mathrm{GHz}$ and $5.2 \mathrm{GHz}$. It may be noted that the dual resonance frequency independent. Finally, to reduce the electrical size of L-loaded IFA, additional inductors are added. Two meandering shape with two unit cells at both open end of the L-loaded IFA as shown in Figure 1(c) are added. Multiband with the reduction in electrical antenna size is created with approximately same antenna parameters. Three-antenna design steps are shown in Figure 2. Figure 2 shows that the conventional IFA resonates at $5.2 \mathrm{GHz}$ while an additional resonant frequency added by loading $\mathrm{L}$ shaped at $3 \mathrm{GHz}$ and kept the first resonant slightly unchanged. The antenna is resonant at multiband by adding a meander line at the open ends of L-loaded IFA at $1.4 \mathrm{GHz}, 2 \mathrm{GHz}, 2.8 \mathrm{GHz}$, 3.2 GHz, $4 \mathrm{GHz}$, and $5.2 \mathrm{GHz}$ with poor antenna matching. 


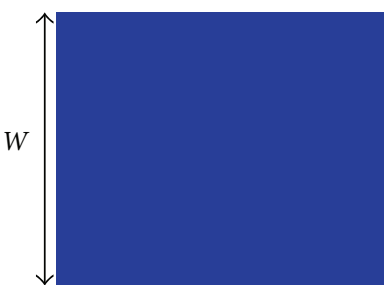

(a)

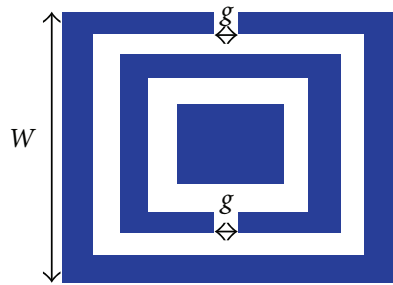

(b)

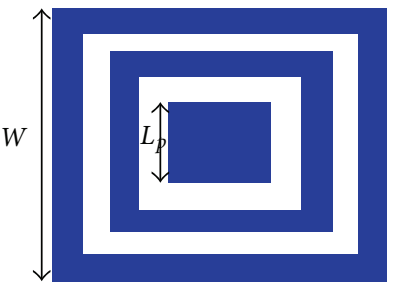

(c)

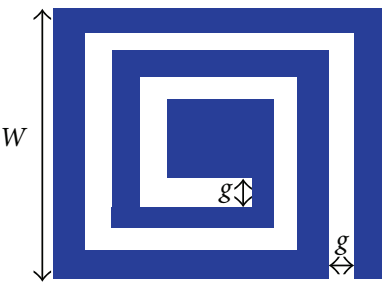

(d)

FIGURE 3: Different unit cell shapes of EBG ground plane mushroom, split ring resonator, ring, and spiral.

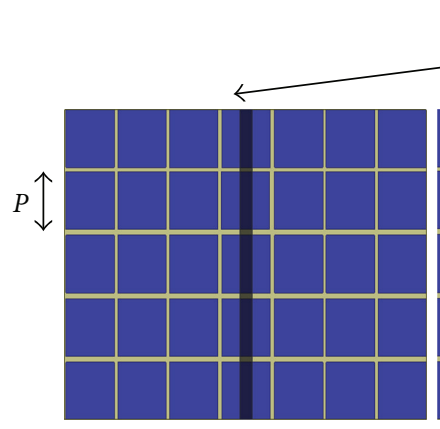

(a)

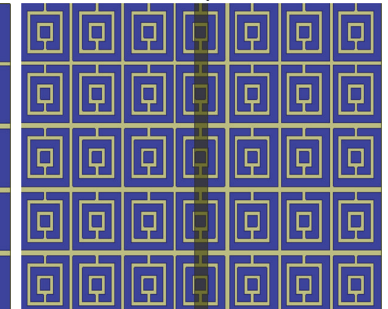

(b)

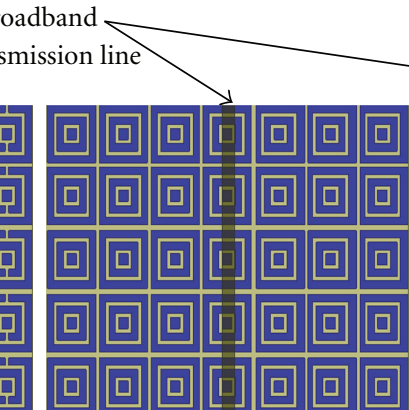

(c)

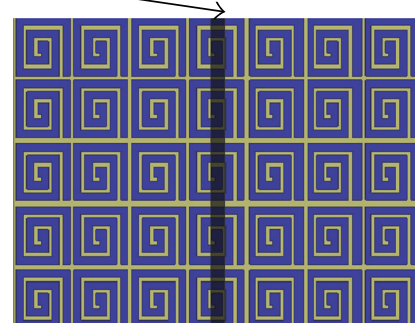

(d)

FIGURE 4: Different shapes of EBG structures (a) mushroom, (b) split ring resonator (SRR), (c) ring, and (d) spiral.

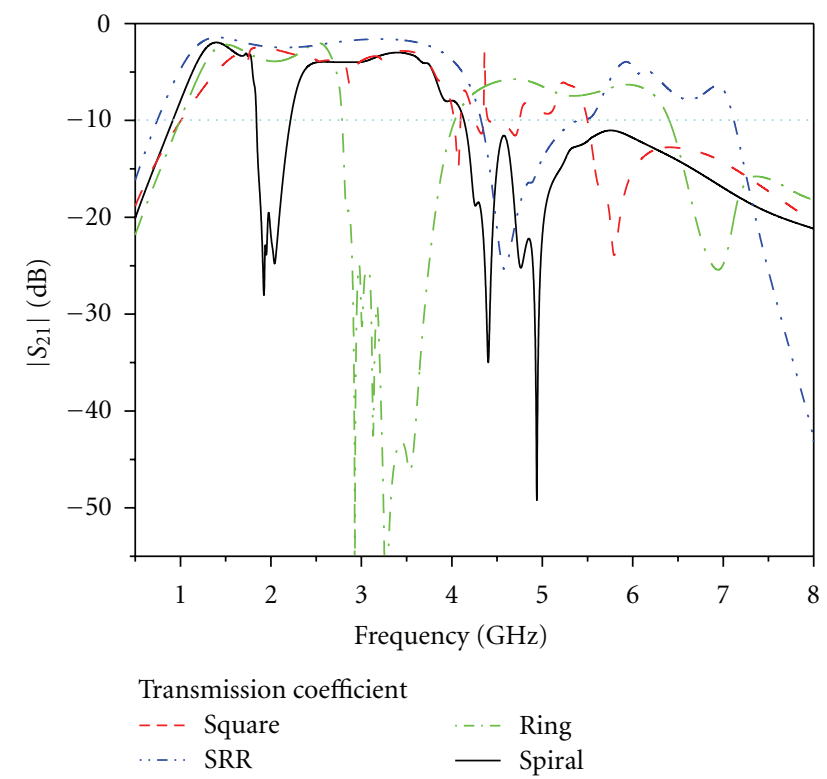

Figure 5: The transmission response for EBG ground, mushroom, split ring resonator, ring, and spiral.

\section{Design of Different Shapes of EBG}

The design of a uniplanar structure of a high impedance surface with compactness is a challenge nowadays. The absence of ground connecting makes the challenge significant, but not impenetrable. Because of the frequency sensitiveness of the surface impedance of the periodic structures like EBG, the configuration must be designed carefully.

Miniaturization and good performance are difficult to achieve simultaneously, particularly at lower frequencies. Some studies have been reported, which improve the performance of patch antennas using periodic structures [8]. In fact, it is well known that a patch antenna on a high dielectric constant substrate is a highly inefficient radiator due to surface wave losses and has a very narrow bandwidth. However, a significant effort has been recently made to realize highperformance antennas employing electromagnetic band-gap (EBG) structures printed on high permittivity substrates.

High-impedance electromagnetic surfaces have been studied by Sievenpiper [7]. In his approach, high-impedance surfaces (in general) consist of a lattice of metal plates, connected to a solid metal sheet

$$
\begin{gathered}
2 W=\lambda_{\text {guid }} \\
\frac{W}{p}=0.8 \sim 0.9,
\end{gathered}
$$

where $W, P$, and $\lambda_{\text {guid }}$ are side length, periodicity, and guided wavelength, respectively [7-12].

In this paper, different shapes of high-impedance surface structures were introduced as mushroom, ring, split ring resonator, and spiral shape cells, respectively, as shown in Figure 3 to produce wide or dual band gaps and as a means to suppress surface waves effectively [18-20]. The configurations of transmission line over the $7 \times 5$ cell arrangement used to test the proposed EBG structures are shown in Figure 4. The design consists of a one-layer substrate; printed on FR4 


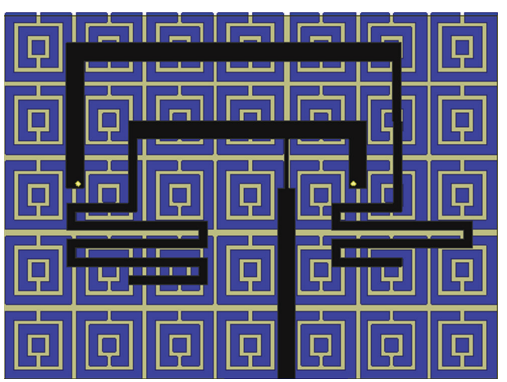

(a)

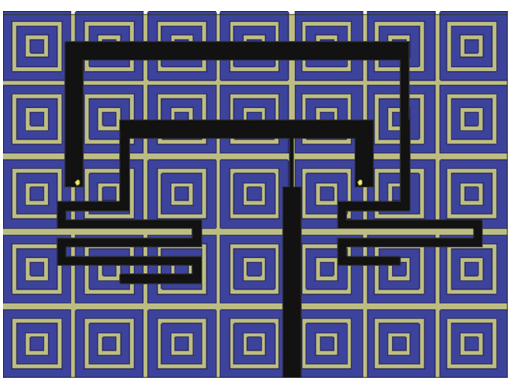

(b)

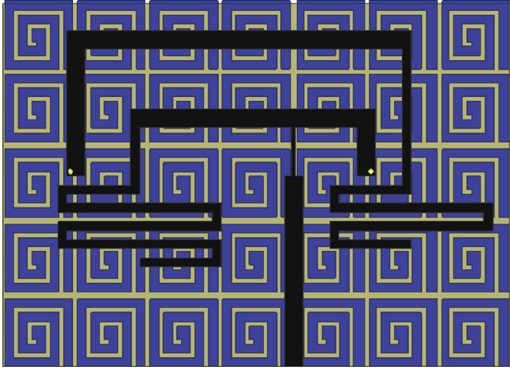

(c)

FIGURE 6: Printed meander L-loaded IFA with different EBG configurations (a) split ring resonator, (b) ring, and (c) spiral.

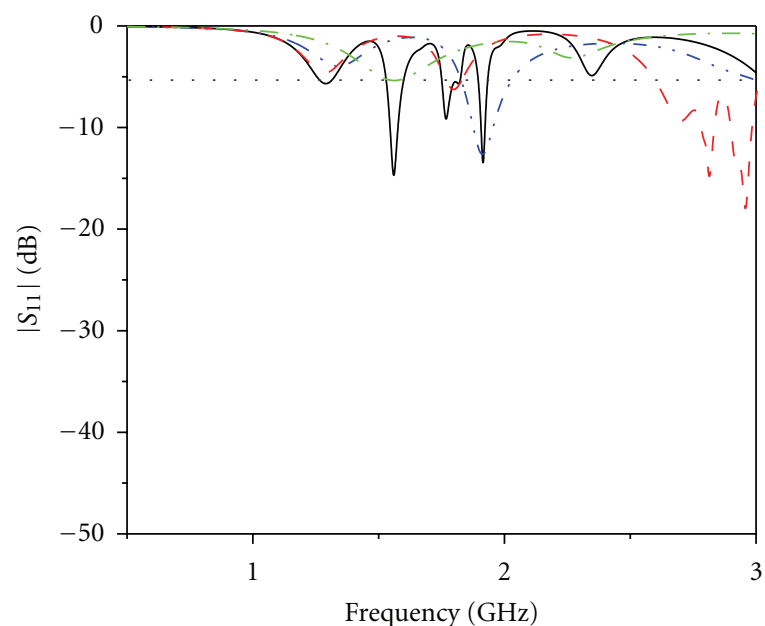

Printed-IFA - - Square SRR

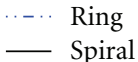

(a)

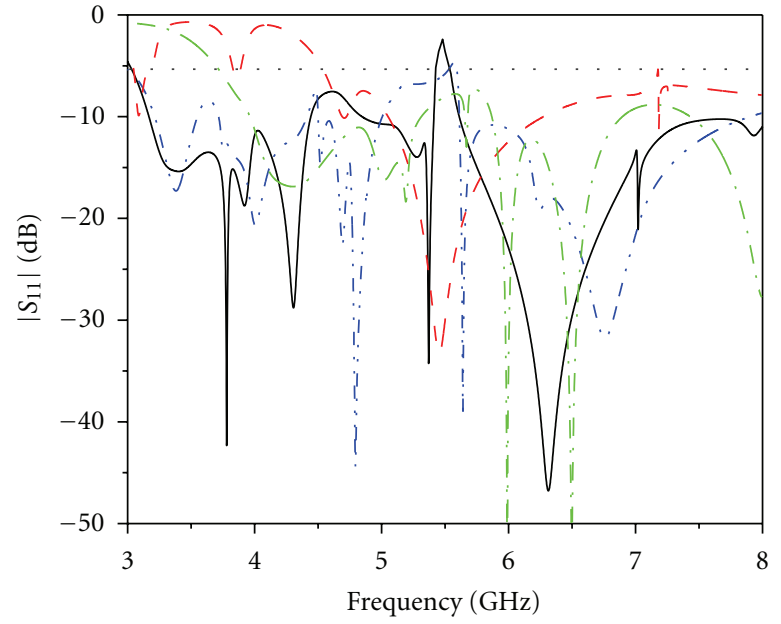

Printed-IFA - - - Square SRR

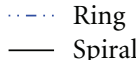

(b)

FIGURE 7: $\left|S_{11}\right|$ of the printed IFA antenna on different uniplanar EBG ground plane shapes.

board of thickness $1.6 \mathrm{~mm}$. This figure represents the metallic periodic structure, which is etched on the dielectric substrate. The main element of this EBG square lattice has side length $W=7.5 \mathrm{~mm}$ and periodicity $P=8 \mathrm{~mm}$. The split ring resonator is etched with gap width and length $g=1 \mathrm{~mm}$. Then ring shape is etched with strip width equal to separation air gap $g=1 \mathrm{~mm}$. Finally, one arm spiral is created to introduce the second band gap. The bandwidth of band gap depends on width of the arm, dielectric constant, and height of the substrate when using $50 \Omega$ broadband transmission lines. The transmission responses of these configurations are shown in Figure 5. This figure shows that the square shape has one band gap started from 4.5 up to $8 \mathrm{GHz}$, while split ring resonator creates two band gaps at 4.5 to $5.5 \mathrm{GHz}$ and from 7.5 to $8 \mathrm{GHz}$, the two-ring EBG shape has a dual band gap started from 2.5 to $4 \mathrm{GHz}$ and from 6.5 to $8 \mathrm{GHz}$. Finally spiral EBG shapes create multiband gap, one at lower frequency from 1.7 to $2.3 \mathrm{GHz}$ and the other started from $4 \mathrm{GHz}$ to $8 \mathrm{GHz}$.

\section{Printed IFA with EBG Ground Plane}

The last step in the proposed antenna design is replacing the conventional antenna ground by $5 \times 7$ patche arrays of highimpedance surface EBG structure to suppress the surface waves and to increase the number of resonant frequencies by means of coupled resonators effect. The EBG lattice is arranged under the radiator. Inductive and capacitive values are added to reduce the antenna size and create multiband. Different shapes of uniplanar EBG ground plane, split ring resonator shape, ring shape, spiral shape, and mushroom shape are applied as a ground plane; all cells have the same dimensions and periodicity. The design started by applying these shapes of EBG ground plane on single printed IFA shown in Figure 1(a). The simulated reflection coefficient is shown in Figure 7. Multibands are generated at a low frequency especially less than $3 \mathrm{GHz}$ by using spiral EBG, while at high frequency the spiral and ring shape give a good performance. Then L-loaded IFA is applied on different 


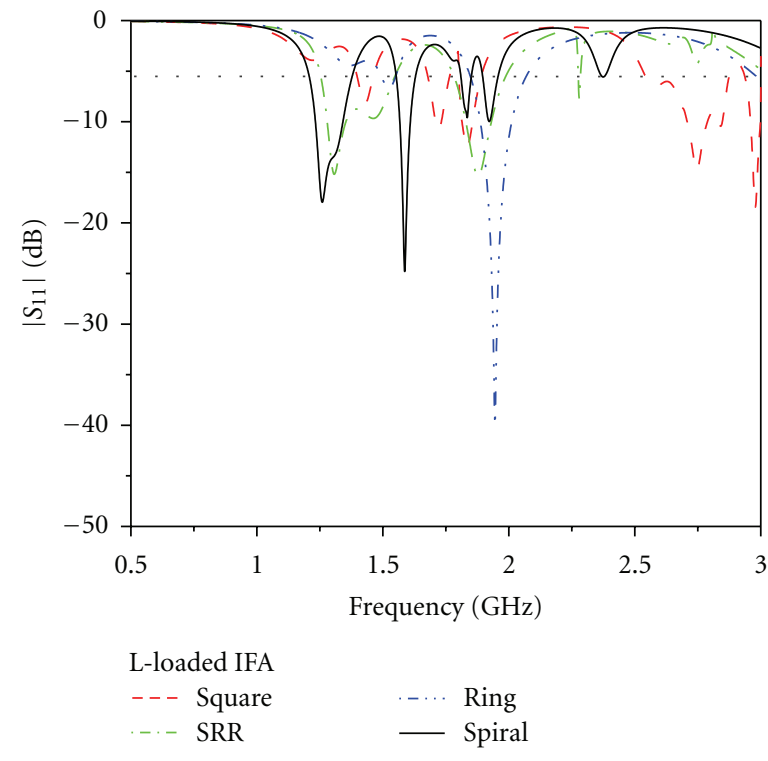

(a)

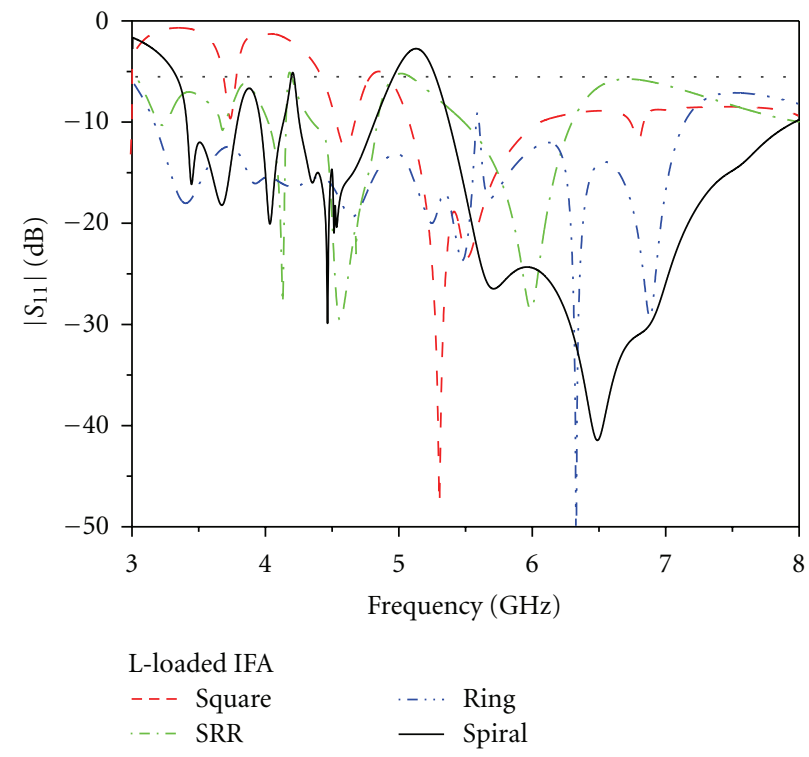

(b)

FIgURE 8: $\left|S_{11}\right|$ of the printed L-loaded IFA antenna on different uniplanar EBG ground plane shapes.

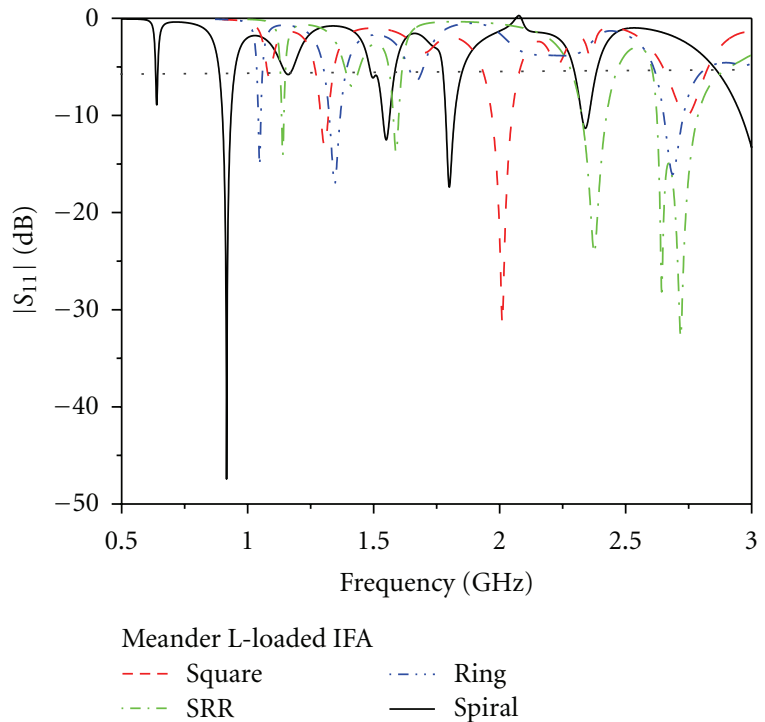

(a)

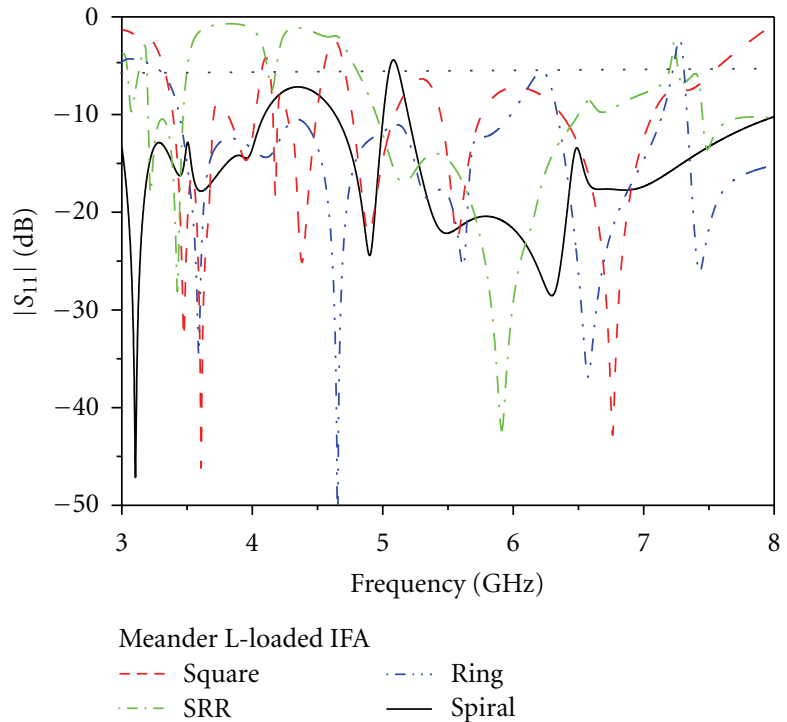

(b)

FIGURE 9: Comparison of $\left|S_{11}\right|$ of the printed meandered L-loaded IFA antenna on different uniplanar EBG ground plane shapes.

TABLE 1: Simulated antenna parameters.

\begin{tabular}{llll}
\hline Antenna Ch/cs. & $\begin{array}{l}\text { Meandered L-loaded IFA } \\
\text { Conventional ground }\end{array}$ & $\begin{array}{l}\text { Final proposed antenna } \\
\text { with ring EBG ground } \\
\text { plane }\end{array}$ & $\begin{array}{l}\text { Final proposed antenna } \\
\text { with spiral EBG ground } \\
\text { plane }\end{array}$ \\
\hline $\begin{array}{l}\text { Resonante Frequency } \\
(\mathrm{GHz})\end{array}$ & $2.65,3,3.6,5.2$ & $\begin{array}{l}0.7,1,1.5,2.5,3,3.6,4.1,5 \\
\text { and } 6\end{array}$ & $\begin{array}{l}0.55,0.9,1.5,1.7,2,2.5,3, \\
3.6,4.1,5 \text { and } 6\end{array}$ \\
Average -6 dB BW & $2 \%$ & $\begin{array}{l}5 \% \text {, and extended from } 3 \text { to } \\
8 \mathrm{GHz}\end{array}$ & $\begin{array}{l}\text { Extended from } 0.5 \text { up to } \\
8 \mathrm{GHz}\end{array}$ \\
$\begin{array}{l}\text { Average Radiation } \\
\begin{array}{l}\text { Efficiency } \\
\text { Average gain }(\mathrm{dBi})\end{array}\end{array}$ & 0.8 & 0.83 & 0.85 \\
\hline
\end{tabular}


TABLE 2: Simulated radiation patterns, antenna with conventional ground - , antenna with ring EBG ground - - and spiral EBG ground - .. -. Axes are shown in Figure 1.

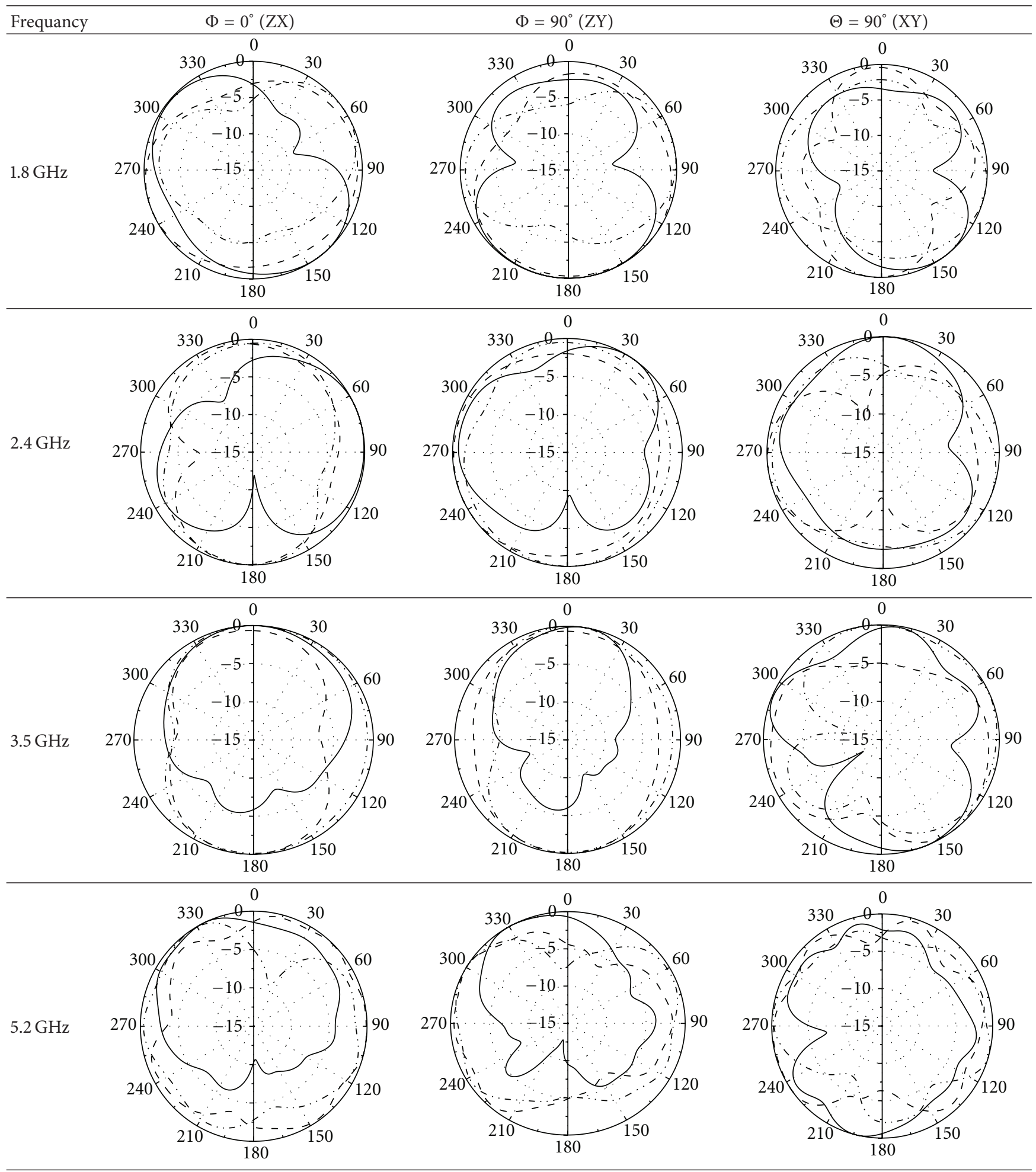




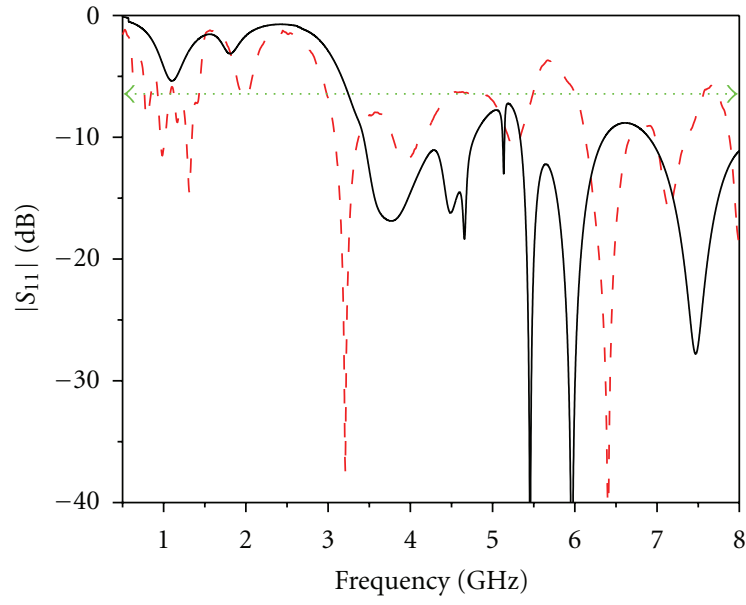

L-loaded IFA

- Simulated

- - Measured

(a)

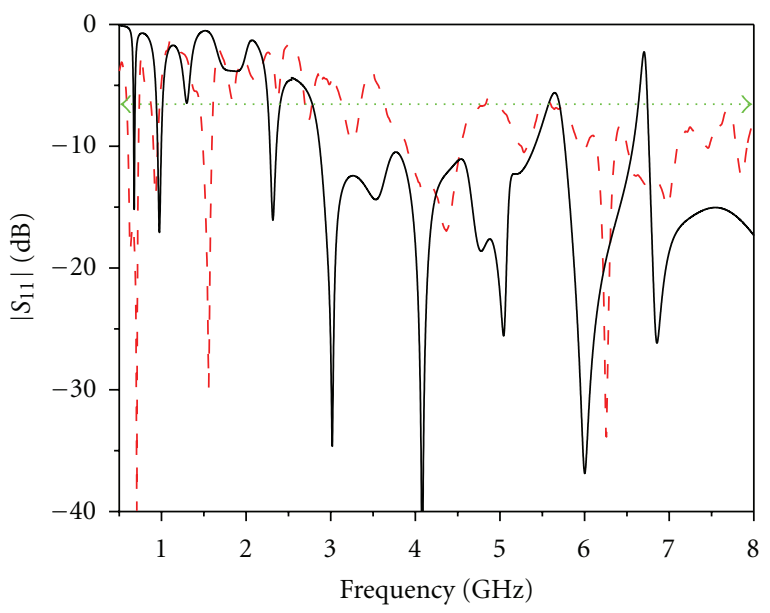

Meander L-loaded IFA

- Simulated

- - - Measured

(b)

FIGURE 10: Comparison between measured and simulated $\left|S_{11}\right|$ of Lloaded IFA antenna with and without meandered shape on ring EBG ground plane.

EBG shapes ground plane shown in Figure 1(b). Simulated $S_{11}$ is shown in Figure 8, the number of antenna resonances is increased especially by using spiral and ring shapes which give a good performance.

By loading meander shapes at the open end of L-loaded IFA antenna, the number of resonances is increased and the antenna matching is improved as shown in Figure 9. Spiral, ring, and split ring resonator give a good performance, respectively, with a good antenna matching. These results could be explained as a spiral shape creates band gap at a lower frequency from 1.5 to $2.5 \mathrm{GHz}$ and band gap opened from $4 \mathrm{GHz}$ to $8 \mathrm{GHz}$, while ring $\mathrm{EBG}$ shape ground plane creates a broad band gap from 2.5 to $4 \mathrm{GHz}$ and another band

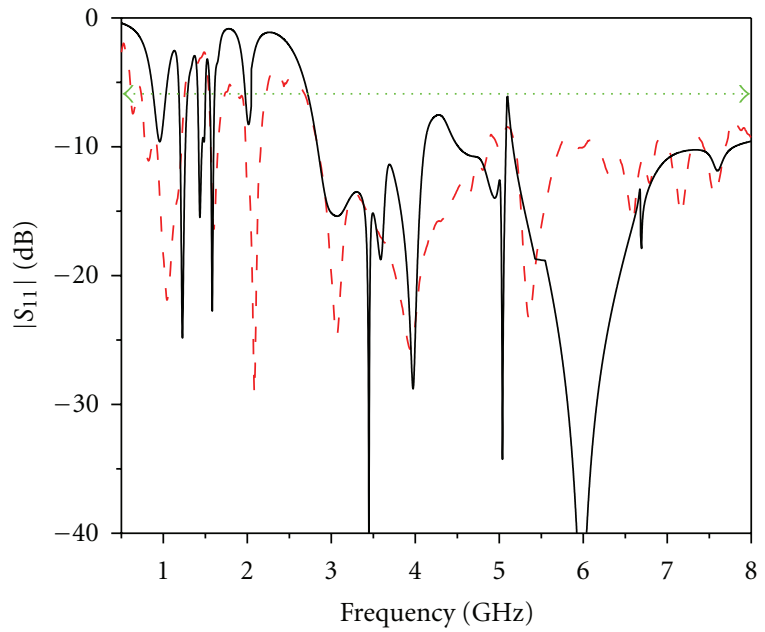

L-loaded IFA

- Simulated

- - Measured

(a)

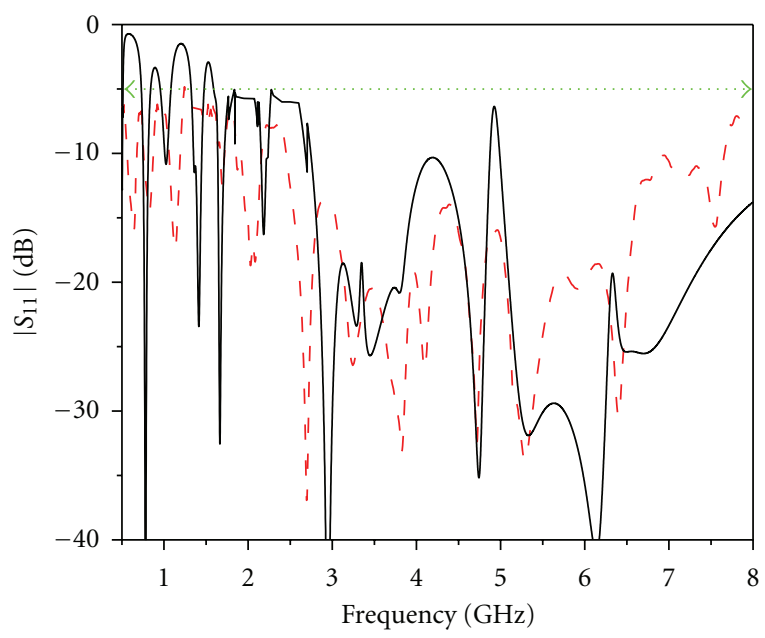

Meander L-loaded IFA

- Simulated

- - Measured

(b)

FIGURE 11: Comparison between measured and simulated $\left|S_{11}\right|$ of Lloaded IFA antenna with and without meandered shape on a spiral EBG ground plane.

gap opened from $6 \mathrm{GHz}$. So, the number of resonant frequencies is increased in this region and by adding inductance and capacitance under the radiator, the antenna size is reduced and the antenna matching is improved.

\section{Simulation and Measurement Results}

The optimized multiband proposed antennas, presented in a previous section, were fabricated on FR4 substrate $\left(\varepsilon_{r}=4.4\right.$, $h=1.6 \mathrm{~mm}$, and $\tan \delta=0.02)$. From the above results, ring and spiral shapes ground plane were selected due to their 


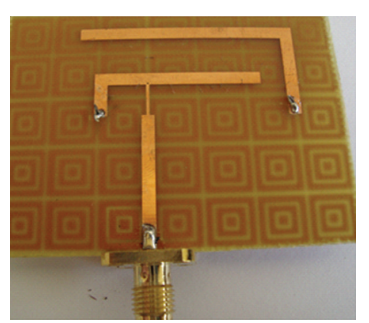

(a)

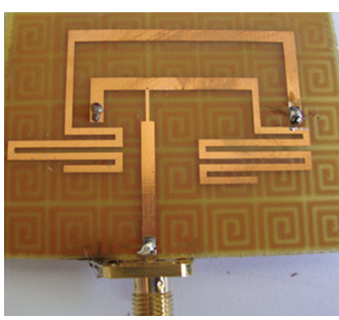

(b)

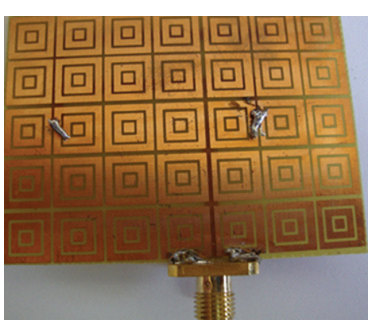

(c)

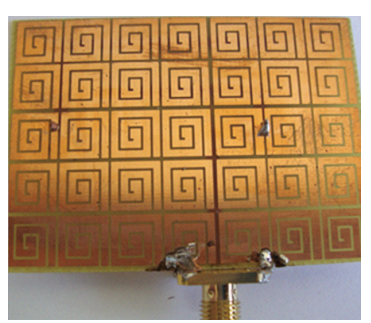

(d)

FIGURE 12: Fabricated antennas, top layer: (a) L-printed-IFA, (b) meander loaded printed IFA, bottom layers, (c) ring-EBG ground plane, and (d) spiral-EBG ground plane.

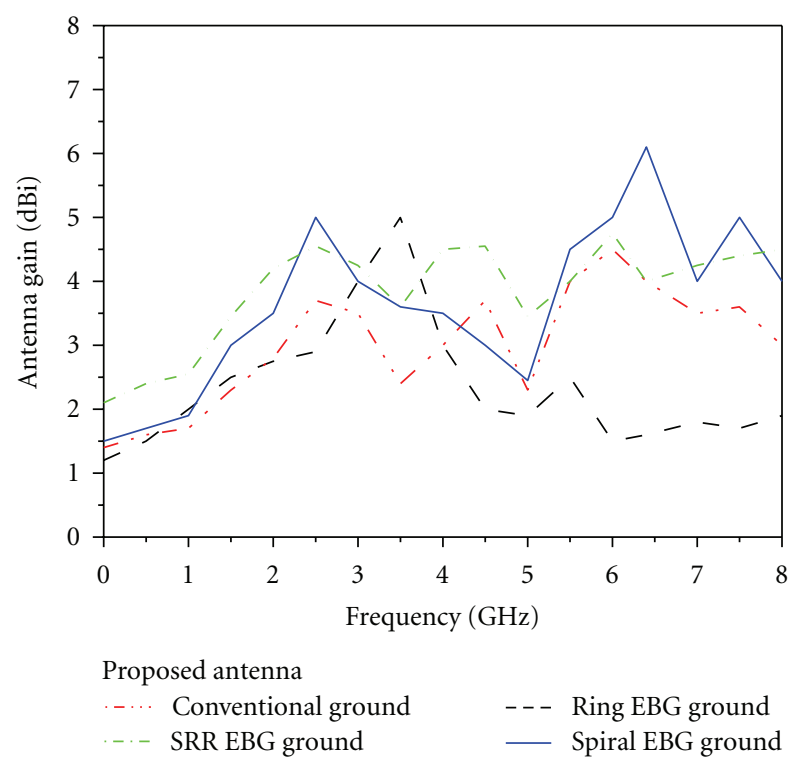

Figure 13: Simulated antenna gain for the meandered L-loaded printed IFA with and without a EBG ground plane.

good performance to be fabricated for both configurations, Lloaded IFA with and without meander shape. The fabricated antenna structures for both upper and lower layers are shown in Figure 6. The comparison between simulated and measured reflection coefficient is shown in Figure 10.

The measurements agree well with EM simulations and show that the operating bands have a return loss better than $-6 \mathrm{~dB}$. When these EBG structures were applied as printed IFA ground plane, the antenna resonant frequencies were reduced due to the capacitive effects that were generated between the two combined structures. Multi-resonant frequencies are achieved at $1.1 \mathrm{GHz}, 1.58 \mathrm{GHz}$, and $2.49 \mathrm{GHz}$ and the bandwidth extended from $3.5 \mathrm{GHz}$ to $5.5 \mathrm{GHz}$ due to number of band-gap stops as shown in Figure 11 for both L-loaded PIFA and meandered L-loaded IFA, respectively. The fabricated antenna is shown in Figure 12. The simulated antenna gain with and without EBG ground plane is shown in Figure 13 and Table 1 . Figure 13 shows that the antenna with spiral EBG ground plane has an average gain greater than the other two shapes. However, the antenna with ring EBG ground plane has gain higher at frequency band from 3 to $4 \mathrm{GHz}$.

Finally, simulated radiation patterns for three antenna planes (ZX, ZY, and XY) are also studied. Comparison of radiation pattern between proposed antenna with and without a EBG ground plane at four different resonant frequencies $1.8 \mathrm{GHz}, 2.4 \mathrm{GHz}, 3.5 \mathrm{GHz}$, and $5.2 \mathrm{GHz}$ is presented in Table 2.

\section{Conclusion}

Multiband compact printed IFAs for the internal mobile phone antenna and wireless applications have been proposed and studied. Three different shapes of EBG rather than mushroom were studied as a printed antenna ground plane. It can be concluded that spiral and ring EBG structures prototype improved the antenna matching, reduced the antenna size, and generated an extra number of resonant frequencies. The operating frequencies are $0.9 \mathrm{GHz}, 1.57 \mathrm{GHz}$, and $2.48 \mathrm{GHz}$, resonant frequencies extended from $3.5 \mathrm{GHz}$ up to $8 \mathrm{GHz}$ for L-loaded printed-IFA spiral EBG ground plane while the lower frequency improved and the higher frequency was slightly unchanged by using meandered L-loaded IFA. EBGprinted IFA provides around an $80 \%$ size reduction, while the antenna characteristics remain almost unchanged. The proposed technique in this paper can be extended to create more operating bands.

\section{Acknowledgment}

This paper is funded by the National Telecommunication Regularity Authority (NTRA), the Ministry of Communication and Information Technology, Egypt.

\section{References}

[1] J. L. Volakis, C. Chih, and K. Fujimoto, Small Antennas: Miniaturization Techniques and Applications, Mc-Graw Hill, New York, NY, USA, 2010.

[2] M. N. M. Kehn, O. Quevedo-Teruel, and E. Rajo-Iglesias, "Reconfigurable loaded planar inverted-F antenna using varactor diodes," IEEE Antennas and Wireless Propagation Letters, vol. 10, pp. 466-469, 2011. 
[3] R. A. Bhatti, Y. T. Im, and S. O. Park, "Compact PIFA for mobile terminals supporting multiple cellular and non-cellular standards," IEEE Transactions on Antennas and Propagation, vol. 57, no. 9, pp. 2534-2540, 2009.

[4] Q. Quevedo-Teruel, E. Pucci, and E. Rajo-Iglesias, "Compact loaded PIFA for multifrequency applications," IEEE Transactions on Antennas and Propagation, vol. 58, no. 3, pp. 656-664, 2010.

[5] K. L. Wong, Compact and Broadband Microstrip Antennas, Wiley-Inter Science, NewYork, NY, USA, 2002.

[6] S. Chaimool, K. L. Chung, and P. Akkaraekthalin, "Bandwidth and gain enhancement of microstrip patch antennas using reflective metasurface," IEICE Transactions on Communications $B$, vol. E93, no. 10, pp. 2496-2503, 2010.

[7] D. Sievenpiper, L. Zhang, R. F. Broas, N. G. Alexöpolous, and E. Yablonovitch, "High-impedance electromagnetic surfaces with a forbidden frequency band," IEEE Transactions on Microwave Theory and Techniques, vol. 47, no. 11, pp. 2059-2074, 1999.

[8] F. Yang and Y. Rahmat-Samii, Electromagnetic Band-Gap Structures in Antenna Engineering: The Cambridge RF and Microwave Engineering Series, Cambridge University Press, Cambridge, Mass, USA, 2008.

[9] F. Yang and Y. Rahmat-Samii, "Curl antennas over electromagnetic band-gap surface: a low profiled design for CP applications," in Proceedings of the IEEE Antennas and Propagation. Society International Symposium, vol. 3, pp. 372-375, July 2001.

[10] J. Y. Park, C. C. Chang, Y. Qian, and T. Itoh, "An improved low-profile cavity-backed slot antenna loaded with 2D UC-PBG reflector," in Proceedings of the IEEE Antennas and Propagation. Society International Symposium, pp. 194-197, July 2001.

[11] F. Yang, V. Demir, D. A. Elsherbeni, A. Z. Elsherbeni, and A. A. Eldek, "Planar dipole antennas near the edge of an EBG ground plane for WLAN applications," in Proceedings of the IEEE Antennas and Propagation Society International Symposium, vol. 1A, pp. 750-753, July 2005.

[12] D. Nashaat, H. A. Elsadek, E. A. Abdallah, M. F. Iskander, and H. M. Elhenawy, "Ultrawide bandwidth $2 \times 2$ microstrip patch array antenna using electromagnetic band-gap structure (EBG)," IEEE Transactions on Antennas and Propagation, vol. 59, no. 5, pp. 1528-1534, 2011.

[13] F. Yang and Y. Rahmat-Samii, "Microstrip antennas integrated with electromagnetic band-gap (EBG) structures: a low mutual coupling design for array applications," IEEE Transactions on Antennas and Propagation, vol. 51, no. 10, pp. 2936-2946, 2003.

[14] S. D. Assimonis, V. Yioultsis, and C. S. Antonopoulos, "Computational investigation and design of planar EBG structures for coupling reduction in antenna applications," IEEE Transactions on Magnetics, vol. 48, pp. 771-774, 2012.

[15] M. Y. Fan, R. Feng, Z. H. Hu, X. X. Zhang, and Q. Hao, "Advance in 2D-EBG research," Journal of Infrared Millimeter Waves, vol. 22, pp. 883-887, 2003.

[16] M. F. Abedin, M. Z. Azad, and M. Ali, "Wideband smaller unit-cell planar EBG structures and their application," IEEE Transactions on Antennas and Propagation, vol. 56, no. 3, pp. 903-908, 2008.

[17] M. Yamamoto and K. T. Nojima, "Leaf-shaped bowtie antenna backed by a periodic patch loaded grounded slab," in Proceedings of the IEEE International Symposium on Antennas and Propagation, pp. 622-625, 2011.

[18] R. C. Hadarig, M. E. de Cos, and F. Las-Heras, "Microstrip patch antenna bandwidth enhancement using AMC/EBG structures,"
International Journal of Antennas and Propagation, vol. 2012, Article ID 843754, pp. 1-6, 2012.

[19] A. Pirhadi, F. Keshmiri, M. Hakkak, and M. Tayarani, "Analysis and design of dual band high directivity EBG resonator antenna using square loop FSS AS superstrate layer," Progress in Electromagnetics Research, vol. 70, pp. 1-20, 2007.

[20] Z. Duan, S. Qu, and Y. Hou, "Electrically small antenna inspired by spired split ring resonator," Progress In Electromagnetics Research Letters, vol. 7, pp. 47-57, 2009. 

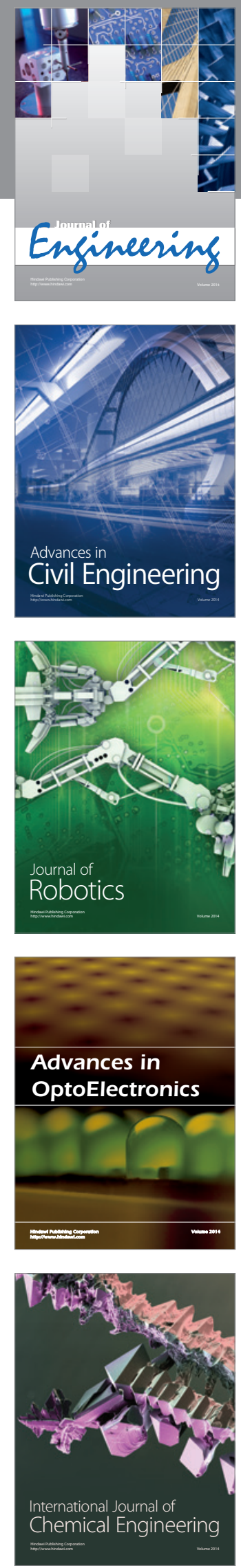

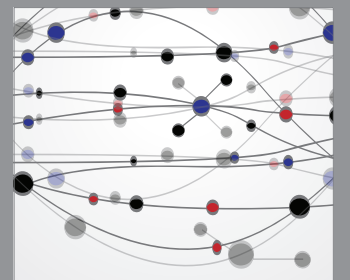

The Scientific World Journal
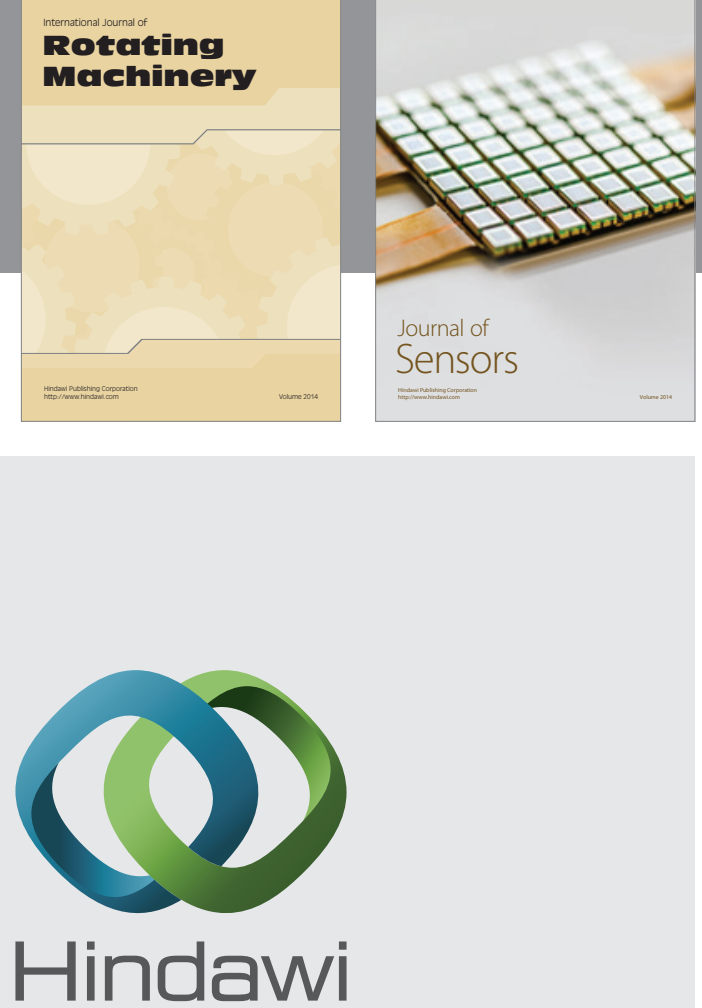

Submit your manuscripts at http://www.hindawi.com
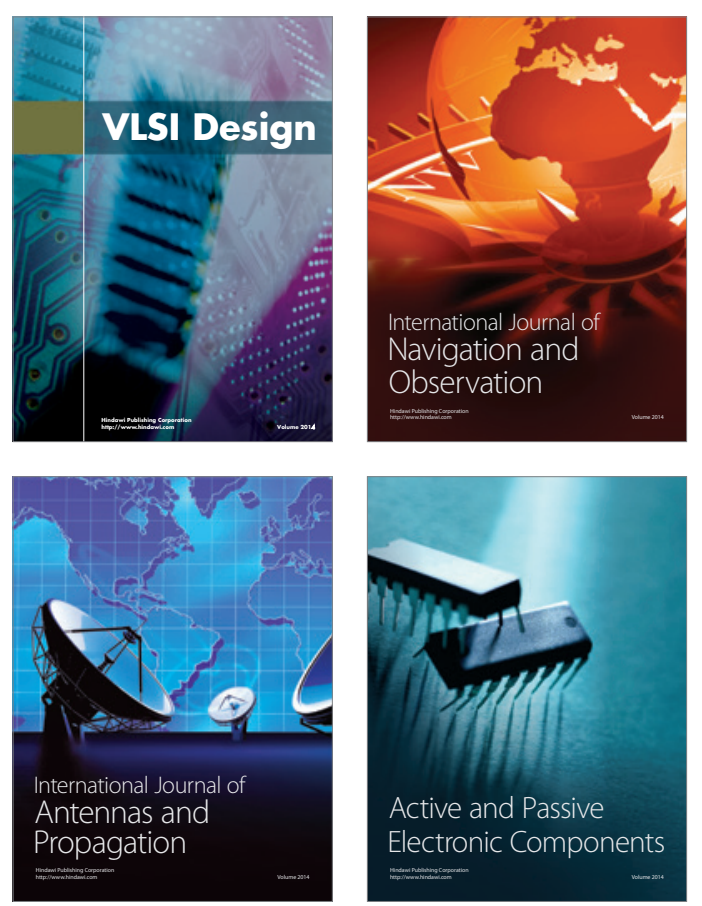
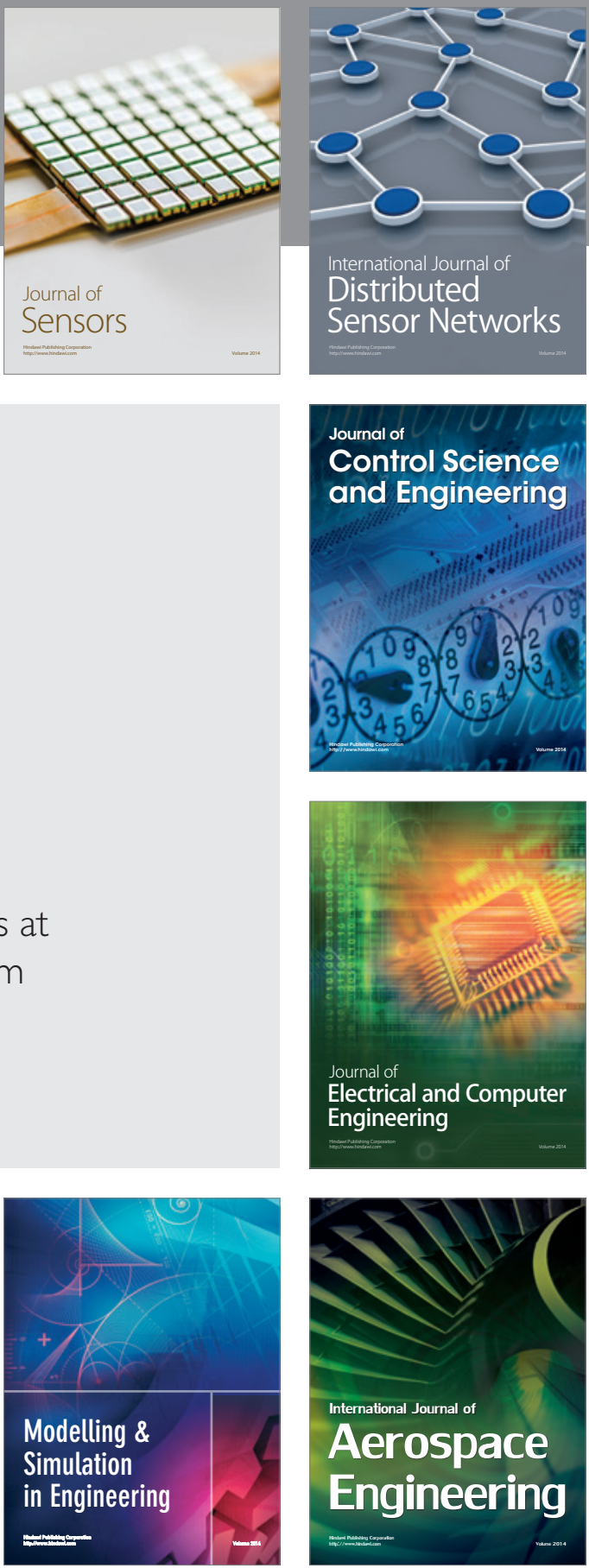

Journal of

Control Science

and Engineering
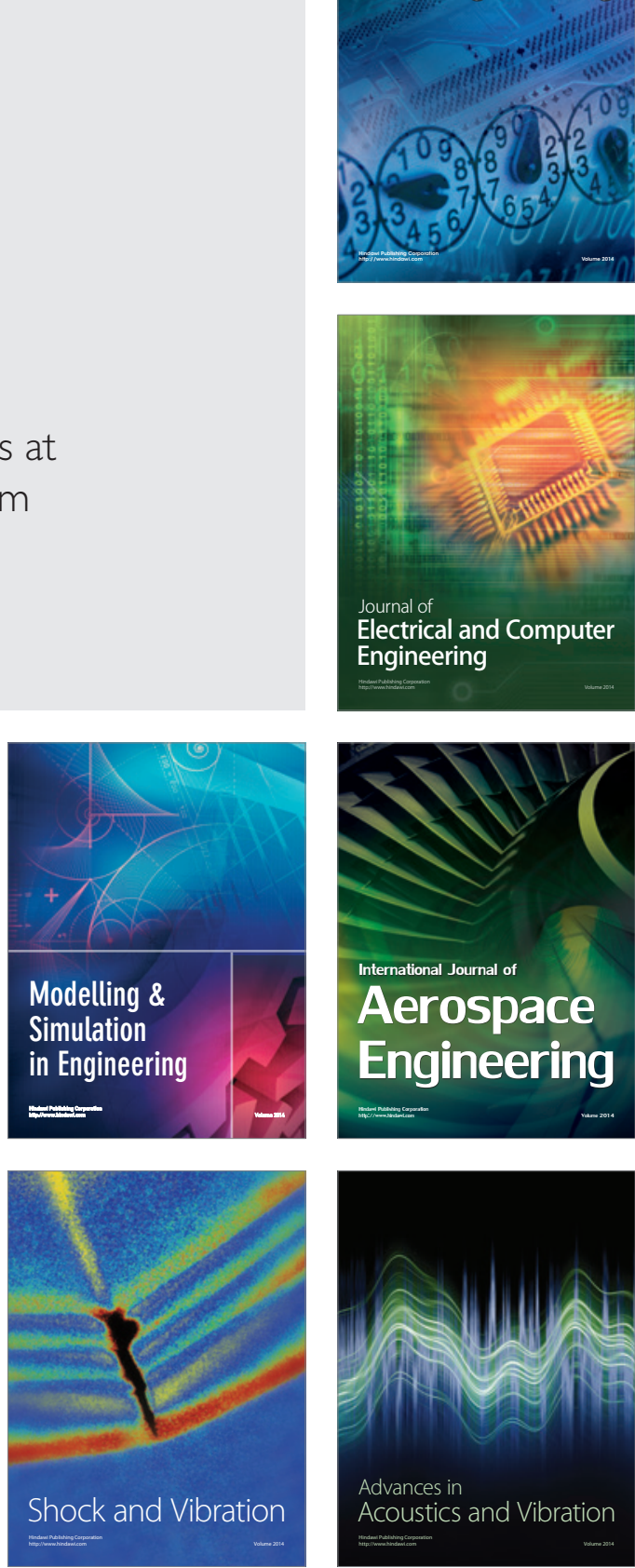